Revista Tecné, Episteme y Didaxis: TED. Año 2014, Número Extraordinario. ISSN Impreso: 0121-3814, ISSN web: 2323-0126

Memorias, Sexto Congreso Internacional sobre Formación de Profesores de Ciencias. 08 al 10 de octubre de 2014, Bogotá

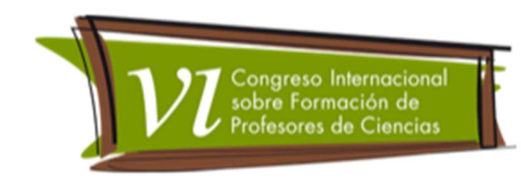

\title{
Análisis de los contenidos CTSA en los libros de texto de química
}

Alba, Diana ${ }^{1}$ y Parga, Diana ${ }^{2}$

Categoría 2. Trabajo de investigación (concluido)

\section{Resumen}

El presente trabajo hace parte de la tesis desarrollada en el marco del programa de Maestría en Docencia de la Química de la Universidad Pedagógica Nacional, en Bogotá. Éste se fundamenta desde la línea de investigación Didáctica de los Contenidos Curriculares del grupo Alternaciencias de esta universidad. Así, la comunicación pretende resaltar los principales aspectos del marco teórico y metodológico en los cuales se enmarca el trabajo y que tienen que ver con la inclusión de los principios del enfoque CTSA en los libros de texto de química de educación media, en la última década (2000-2010). Así mismo, intenta caracterizar los contenidos CTSA presentes en ellos.

\section{Palabras Claves}

Enfoque CTSA, libros de texto, contenidos CTSA.

\section{Objetivos de la investigación}

El trabajo de tesis plantea analizar y proponer la inclusión de los principios del enfoque CTSA en los libros de texto de química de educación media de la última década y las características de los contenidos CTSA presentes en ellos. Para ello pretende:

- Caracterizar los componentes del enfoque CTSA en los libros de texto de química de grado décimo objeto de investigación.

- Determinar los criterios de selección de los contenidos CTSA en los libros de texto.

- Analizar la evolución que han tenido los libros de texto de química del grado décimo y undécimo respecto al enfoque CTSA como injerto, ciencia desde el enfoque CTSA y CTSA puro.

\footnotetext{
1 Candidata a Magíster en Docencia de la Química. Universidad Pedagógica Nacional. Colombia dianis1023@hotmail.com

2 Profesora del Departamento de Química. Universidad Pedagógica Nacional. Colombia. dparga@pedagogica.edu.co
} 
Revista Tecné, Episteme y Didaxis: TED. Año 2014, Número Extraordinario. ISSN Impreso: 0121-3814, ISSN web: 2323-0126

Memorias, Sexto Congreso Internacional sobre Formación de Profesores de Ciencias. 08 al 10 de octubre de 2014, Bogotá

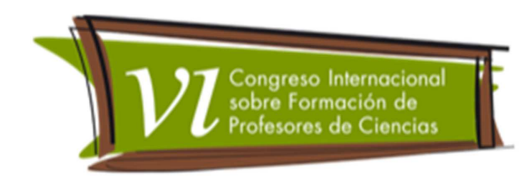

- Proponer lineamientos para el diseño de los libros de texto con enfoque CTSA propios del contexto colombiano.

\section{Orígenes del movimiento cts}

En los años cincuenta surgen los primeros programas STPP (Science, Tecnologhy and Public Policy), o SEPP (Sciencie Engineering and Public Policy Studies) orientado para formar científicos e ingenieros en los campos de la política y un enfoque tecnocrático en universidades tecnológicas con el fin de dar respuestas a la tecnociencia (Acevedo, Manassero, y Vásquez, 2001).

El movimiento CTS tiene sus antecedentes en el STPP, pero a su vez incorpora el componente crítico en investigaciones teóricas respecto al contexto social y cultural de la ciencia y la tecnología. En los años 60 inicio con la contraposición a explicaciones internalistas de la ciencia y la tecnología a partir de los sucesos sociales que se presentaron como las revueltas estudiantiles, movimientos contraculturales, entre otros.

El programa ciencia, tecnología y sociedad nace al final de los años 60 y comienzos de los años 70 e inicia con la alfabetización científica tecnológica centrada en la educación para una ciudadanía responsable e inteligente en medio de una sociedad con un alto componente científico y tecnológico, por lo cual los programas STS fueron una extensión de los programas STPP y un movimiento de oposición contra los efectos de la ciencia y la tecnología con aproximaciones culturales citado por (Acevedo, Manassero, y Vásquez,2001). De acuerdo con esto, el enfoque CTS se da en dos sentidos: el primero viene desde las ciencias sociales con la intencionalidad de concientizar a los científicos e ingenieros y el otro desde las ciencias experimentales y la tecnología para proporcionar una mejor comprensión de estas y como pueden contribuir en la solución de problemas sociales.

\section{Materiales curriculares para el enfoque CTS: enfoques y contenidos}

De acuerdo con la revisión realizada, se encuentra que hay investigadores que están de acuerdo con la necesidad de prestar una mayor atención a los contenidos abordados en el aula de clase en ciencias y particularmente para la química, pero pese a esta preocupación estos contenidos siguen aun sin ser abordados y la educación desde el enfoque CTS es una de esas innovaciones a nivel curricular (Acevedo y Acevedo, 2002) que aún falta por imlementar en el ámbito colombiano. 
Revista Tecné, Episteme y Didaxis: TED. Año 2014, Número Extraordinario. ISSN Impreso: 0121-3814, ISSN web: 2323-0126

Memorias, Sexto Congreso Internacional sobre Formación de Profesores de Ciencias. 08 al 10 de octubre de 2014, Bogotá

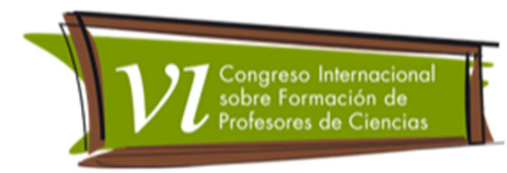

De otra parte, uno de los obstáculos que encuentran los docentes al momento de introducir nuevas innovaciones es la falta de tiempo, los recursos y lo más importante los materiales para poder introducir dichas actividades y planificarlas para llevarlas a cabo. Además, es evidente que uno de los problemas que afrontan los estudiantes en las clases de ciencias es que los contenidos impartidos son abstractos, centrados únicamente en los disciplinar, por tanto existe una preocupación porque no hay una contextualización de los mismos y desde esta óptica, el estudiante cuando ve la relación de la ciencia con su entorno, en este caso de la química en particular, la tecnología y la sociedad, puede tener un mejor aprendizaje.

Dado lo anterior, han sirgido distintas asociaciones en el ámbito internacional y nacional que se han preocupado por el estudio y la implementación de programas en educación desde el enfoque CTS, entre ellos puede señalarse los trabajos de Acevedo y Acevedo (2002), entre otros.

- La ASE (Association for Science Education) en Gran Bretaña.

- La internacional IOSTE (International Organization of Science and Technology Education) con Sede en Canadá.

- La NASTS (National Association for Science, Technology and Society) en los EE.UU.

- La Europea EASTS (European Association of STS) en la cual Holanda es uno de los principales líderes.

- La OEl (Organización de Estados Iberoamericanos para la Educación, la Ciencia y la Cultura) con su programa Ciencia, Tecnología Sociedad e Innovación (CTS+l).

\section{Referente Metodológico}

El presente trabajo de investigación es de carácter descriptivo, esto en términos de utilizar técnicas de análisis de contenido de libros de texto (Malavér, Pujol y D’Alessandro, 2004) que permiten la recopilación de datos a fin de estudiar las características de dicho contenido, clasificando sus partes de acuerdo con las a categorías establecidas (Ander-Egg, 1980; Ruiz Olabuenaga, 1996, citado por Malavér, Pujol y D’Alessandro, 2004). El análisis de contenido es una de las técnicas más elaboradas, es una técnica para estudiar y analizar de manera objetiva y sistemática un contenido manifiesto a fin de ser interpretado. Por otro lado, Krippendorff (1990) define el análisis de contenido como "una técnica de investigación destinada a formular, a partir de ciertos datos, inferencias reproducibles y validas que pueden aplicarse a su contexto" (pág. 55). 
Revista Tecné, Episteme y Didaxis: TED. Año 2014, Número Extraordinario. ISSN Impreso: 0121-3814, ISSN web: 2323-0126

Memorias, Sexto Congreso Internacional sobre Formación de Profesores de Ciencias. 08 al 10 de octubre de 2014, Bogotá

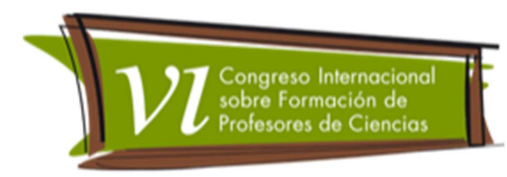

De acuerdo con lo mencionado, se incluyen algunas características importantes del análisis de contenido expuestas por Berelson y Holsti en López (1986):

- Fondo de los contenidos: se emplea para describir tendencias y cambios en el contenido de las comunicaciones, con el fin de indagar la evolución de los intereses y las actividades del pensamiento.

- Forma de los contenidos: se centraría en revelar rasgos en lenguajes históricos y tipos de discursos.

\section{Fases de la investigación}

Las fases que hacen parte de la metodología son:

\section{- Establecer unidades de análisis}

Esta consiste en establecer fragmentos que son tomados como elementos que hacen parte de la investigación. Según Strube (1989) una unidad de análisis, es una unidad en prosa, la cual incluye una sola idea, según este autor las secciones están marcadas por tipografías, es decir, donde aparecen encabezados con letras cursivas o por subencabezados, los cuales indican una clara separación física entre las distintas secciones del libro de texto y quedan a juicio del investigador el escoger en donde termina y en donde comienza la sección para ser analizada.

\section{- Determinar las categorías de análisis}

De estas categorías depende la clasificación y la selección de la información buscada de acuerdo con los parámetros establecidos por una matriz para el análisis de los aspectos CTS en los libros de texto.

Para esta sección se puede tener en cuenta lo planteado por Malavér, Pujol y D' Alessandro, 2004) dentro de su investigación, quienes determinan para su estudio la interrelación ciencia, tecnología y sociedad. En este estilo en prosa se trabaja el impacto que ha tenido la ciencia y la tecnología en la sociedad y en el ambiente. Bajo este aspecto se busca conocer si se discuten y se muestran algunos ejemplos de las aplicaciones de la ciencia y a la vez de determinar cuál es el uso que los seres humanos le dan a la tecnología, en términos de si estas ayudan o por el contrario perjudican no solo el medio si no a la humanidad en general.

A continuación se detalla lo que se realizará con el análisis de contenido: 
Revista Tecné, Episteme y Didaxis: TED. Año 2014, Número Extraordinario. ISSN Impreso: 0121-3814, ISSN web: 2323-0126

Memorias, Sexto Congreso Internacional sobre Formación de Profesores de Ciencias. 08 al 10 de octubre de 2014, Bogotá

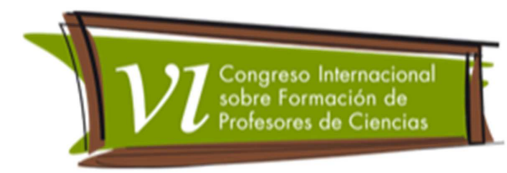

- Descomposición en unidades de codificación: para este se entiende que se realiza la descomposición en unidades de codificación aquellas unidades del texto que posteriormente serán codificadas de forma manual.

- Codificación: la codificación es el proceso conforme al cual un "dato sin procesar se transforma y agrega de forma sistemática en unidades que permiten una descripción precisa de las características esenciales del contenido" (Holsti, 1969: 94; citado por Alonso, Volknes y Gómez, 2012).

De acuerdo con lo anterior la descomposición en unidades de codificación se realizará una vez se tengan los texto a ser analizados y se hará según las categorías de análisis planteadas; en esta se tomarán los fragmentos de textos que sean escogidos dentro de los distintos libros y los criterios establecido para cada una de las unidades de análisis.

Por otro lado, la codificación se llevará a cabo una vez se hallan seleccionado los fragmentos de texto en términos de identificar qué tanto se repiten o se encuentran las categorías de análisis propuestas, estos con su respectivo análisis en torno también a los criterios de análisis.

En cuanto a la codificación manual: en este tipo de codificación la fiabilidad del estudio depende por una lado de la claridad de las categorías que se han establecido para el análisis, es así como desde esta perspectiva el método es un enfoque cualitativo (Alonso, Volknes y Gómez, 2012).

La muestra objeto de estudio son los libros de texto de grado décimo más empleados por los docente de educación media.

\section{Categorías de análisis para el enfoque CTSA en los libros de texto}

De acuerdo con el enfoque teórico propio del enfoque CTSA en la enseñanza de las ciencias en secundaria, existen tres categorías en los cuales se pueden clasificar los programas CTSA: introducción CTSA en los contenidos de las asignaturas de ciencias (injertos CTSA), la ciencia a través de CTSA), CTSA pura (González, López y Lujan, 2000) y por último, los contenidos estructurales CTSA que son un contenido planteado por la investigadora. A continuación se presentan las unidades de análisis con sus respectivas categorías de análisis que se emplearan en la matriz de evaluación para los libros de texto: 
Revista Tecné, Episteme y Didaxis: TED. Año 2014, Número Extraordinario. ISSN Impreso: 0121-3814, ISSN web: 2323-0126

Memorias, Sexto Congreso Internacional sobre Formación de Profesores de Ciencias. 08 al 10 de octubre de 2014, Bogotá

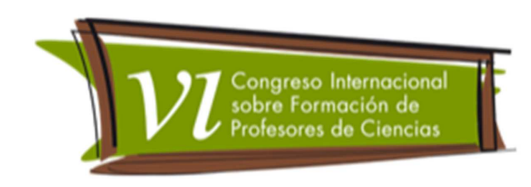

\section{Unidad de análisis a: Injerto ctsa}

Este consiste en presentar la ciencia de modo usual y hacer algunos añadidos CTSA, se mencionan contenidos CTSA para hacer más interesantes los temas que son netamente de carácter científico o en el mejor de los casos complementar los contenidos científicos con estudios breves CTSA específicos. Las categorías definidas para este son: Aplicaciones de la ciencia, Aplicaciones de la tecnología e Implicaciones de la ciencia y la tecnología en la sociedad.

\section{Unidad de análisis b: Ciencia a través de ctsa}

Ciencia y tecnología a través de CTSA: la ciencia y la tecnología enseñada a través de CTSA bajo esta orientación significa estructurar los contenidos desde la disciplinariedad, sus categorías de análisis son: contenidos disciplinares a partir de CTSA, Contenidos tecnológicos a partir de CTSA y Contenidos sociales a través de CTSA.

\section{Unidad de análisis c: Ctsa pura}

Significa enseñar CTSA en donde el contenido científico va a tener un papel subordinado. En algunos casos el contenido científico se incluye con el fin de enriquecer la explicación de los contenidos CTSA; en otros se referencia a los temas de carácter científico o tecnológico, pero sin explicarlos. Sus categorías de análisis son: Contenidos centrados en los disciplinar, Contenidos tecnológicos subordinados, Contenidos que implican CTS

\section{Unidad de análisis d: Contenidos estructurales ctsa}

Este tipo de contenidos consiste en presentar la importancia de la preocupación por los asuntos sociales hacia la ciencia y la tecnología, en este se tiene en cuenta aspectos de carácter transversal como la educación para la salud y la educación ambiental, los aspectos sociológicos e históricos de la ciencia y la tecnología, sus categorías de análisis son: Inserción ocasional o intencionada en los cursos de ciencia y tecnología, Naturaleza de la ciencia y la tecnología, Cuestiones sociales de la ciencia y la tecnología.

Es de aclarar que en la investigación pueden surgir otras categorías de análisis además de las presentadas anteriormente. 
Revista Tecné, Episteme y Didaxis: TED. Año 2014, Número Extraordinario. ISSN Impreso: 0121-3814, ISSN web: 2323-0126

Memorias, Sexto Congreso Internacional sobre Formación de Profesores de Ciencias. 08 al 10 de octubre de 2014, Bogotá

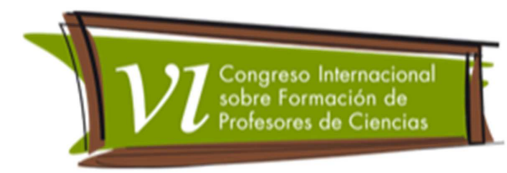

\section{Conclusiones preliminares}

Respecto a los resultados del presente trabajo, se espera encontrar que en los últimos 10 años, en los libros de texto de química en Colombia, los contenidos CTSA aparecen como añadido y tienden a ser abordados al comienzo o final de un capítulo pero no se articulan dentro de los contenidos curriculares de la química y es posible que los presupuestos para los cuales fueron planteados estos contenidos, tales como la alfabetización, enculturación, sean poco desarrollados en el estudiantado, en tanto encuentre estos contenidos desarticulados y descontextualizados de los demás.

\section{Referencias bibliográficas}

Acevedo, J.; Manassero, M.; Y Vásquez, A. (2001). El movimiento ciencia -tecnología sociedad y la enseñanza de las ciencias. En http:/www.campus.oei.org/salactsi/.htm.

Acevedo, P. y Acevedo. J. (2002). Proyectos y materiales curriculares para la educación CTS: enfoques, estructuras, contenidos y ejemplos. En http://www.oei.es/salactsi/acevedo19.htm

Alonso, S.; Volkens. A. y Gomez, B. (2012). Análisis de contenido de textos políticos, un enfoque cuantitativo. Colección de cuadernos metodológicos, número 47. Montalbán, Madrid: Primera edición.

Campanario, J.; Otero, J. (2000). La compresión delos libros de texto. Handbook. Parte II. El currículo de ciencias experimentales. Capítulo 14, p. 323-338.

Krippendorff, K. (1990). Metodología de análisis de contenido. Teoría y Práctica. Barcelona: Paidós Ibérica, S.A.

López, E. (1986). El análisis de contenido tradicional. En M. García, J. Ibañez, y F. Alvira, El análisis de la realidad social. Métodos y técnicas de investigación (Tercera ed.). Alianza Editorial.

Malaver. M.; Pujol. R. ; y D`Alessandro, A. (2004). Los estilos en prosa y el enfoque ciencia-tecnología-sociedad en textos universitarios de química general. Revista enseñanza de las ciencias. v. 22, n.3, pág. 441-454

Martínez, L. y Parga, D. (2013). La Emergencia de las Cuestiones socio científicas en el enfoque CTSA. En Góndola v. 8, n. 1, pág. 23-35. 
Revista Tecné, Episteme y Didaxis: TED. Año 2014, Número Extraordinario. ISSN Impreso: 0121-3814, ISSN web: 2323-0126

Memorias, Sexto Congreso Internacional sobre Formación de Profesores de Ciencias. 08 al 10 de octubre de 2014, Bogotá

Membiela. P. (1997). Una revisión del movimiento educativo ciencia-tecnologíasociedad. En revista enseñanza de las ciencia v. 15, n. 1, pág. 51-57

Strube, P. (1989). A content analysis of argument and explanation present to students in physical science text-books: a model and example. International Journal of Science Education, 11(2), pág. 195-202.

Valladares. J. (2000). El análisis de los libros de texto. Handbook. Parte II. El currículo de ciencias experimentales. Capítulo 13, pág. 309-322. 